\title{
A guide towards climate change adaptation in the livestock sector: adaptation options and the role of robust decision-making tools for their economic appraisal
}

\author{
Ruth Dittrich $^{1,2}$ - Anita Wreford ${ }^{1,3}$ - Cairistiona F. E. Topp ${ }^{1}$ Vera Eory $^{1}$ • \\ Dominic Moran ${ }^{1}$
}

Received: 14 May 2015/Accepted: 9 January 2017/Published online: 3 March 2017

(c) The Author(s) 2017. This article is published with open access at Springerlink.com

\begin{abstract}
Economic appraisal and technical effectiveness of adaptation options are key criteria for judging climate change adaptation investment decisions in all sectors. Yet relatively little methodological guidance exists for determining the most appropriate appraisal techniques for different adaptation options. This paper provides adaptation options and scopes relevant appraisal methods in agriculture focussing on livestock production specifically. We find that for many adaptation options for livestock agriculture, standard (expected) cost-benefit analysis is an appropriate tool. For adaptation options requiring long lead times or those with long lifetimes, techniques incorporating uncertainty ('robust' methods) are more suitable, including real options analysis, portfolio analysis and robust decisionmaking. From a comprehensive list of adaptation options in
\end{abstract}

Ruth Dittrich

ruth.dittrich@sruc.ac.uk

Anita Wreford

anita.wreford@scionresearch.com

Cairistiona F. E. Topp

kairsty.topp@sruc.ac.uk

Vera Eory

vera.eory@ sruc.ac.uk

Dominic Moran

dominic.moran@sruc.ac.uk

1 Land Economy, Environment and Society Research Group, Scotland's Rural College, West (SRUC), Kings Buildings, West Mains Road, Edinburgh EH9 3JG, UK

2 Pamplin School of Business, University of Portland, $5000 \mathrm{~N}$ Willamette Blvd, Portland, OR 97203, USA

3 Scion, Forestry Building, Forestry Road, IIam, Christchurch 8041, PO Box 29237, Riccarton, Christchurch 8440, New Zealand the livestock sector, we identify the most appropriate appraisal technique for each option and describe how the robust appraisal tools could be applied to heat stress, flood risk and water management.

Keywords Livestock · Economic appraisal · Climate change adaptation $\cdot$ Robust methods

\section{Introduction}

Agriculture is especially vulnerable to climate change due to its dependence on climate-sensitive natural resources (Howden et al. 2007). Climatic changes are already being experienced: across Europe, the average decadal temperature for 2002-2011 was $1.3 \pm 0.11^{\circ} \mathrm{C}$ above the 1850-1899 average and since the 1950s annual rainfall has increased over Northern Europe and decreased over Southern Europe, as well as an increase in extreme conditions. Temperatures are projected to rise by between 1 and $4{ }^{\circ} \mathrm{C}$ per century across Europe, and precipitation to increase in Northern Europe and decrease in Southern Europe (Kovats et al. 2014).

The projected changes, including the effects of climate variability and extremes, will have direct effects on livestock productivity, either on the animal directly (e.g. through heat stress) or indirectly through effects on crop production and the disease vectors to which the livestock are exposed. For example, increases in winter temperature will lengthen the thermal growing season in regions where temperature constrains crop growth during winter. But higher temperatures during the growing season may result in yield reduction as experienced during the heat waves of 2003 and 2010 when grain losses reached 20\% in Europe (Kovats et al. 2014). The livestock sector contributes 
substantially to the European economy ( $€ 169.5 b n$ in 2013), being $41 \%$ of total agricultural value (FEFAF 2013) and creating employment among the 10 million people working full-time and 25 million people working part-time in agriculture in Europe (European Commission 2013b). Further, demand for livestock products is likely to increase in the future, particularly in developing countries (Thornton 2010). Thus, given the economic importance of the livestock sector in Europe, minimising the impact of climatic changes on its output through effective and strategic implementation of adaptive practices will be critical. Adaptation options are wide-ranging, from incremental changes in management in current systems, to long-term structural and transformative changes in the farm as well as the sector as a whole, with a growing body of research identifying options and their effectiveness (e.g. Renaudeau et al. 2012; Hoving et al. 2014).

Decision-makers in agriculture, from farmers to policymakers, require information on the anticipated costs and benefits of adaptation, in order to evaluate the most economically efficient adaptation options. Economic appraisal methods synthesise the effects of adaptation options on production, farm businesses and risks in order to fully evaluate adaptation options. Planning for adaptation requires some foresight that the climate will change in the future, or if changes are already being observed, that these changes will continue. The Ricardian approach (Mendelsohn and Nordaus 1994; Seo and Mendelsohn 2008) measures empirically the economic impact of climate change on land prices and controls for adaptation and has shown that farmers adapt to climate change to address changes in economic return caused by climate variables. While significant advances have been made in projecting future climate scenarios [e.g. CMIP5 scenarios (Taylor et al. 2012)], these projections, as well as their implications for agricultural systems, are associated with considerable uncertainty that can pose challenges for decision-making.

Uncertainty in climate projections stems from four main sources: (1) modelling uncertainty, which arises from our incomplete understanding of the climate system and the inability of climate models to represent the real system perfectly; (2) natural climate variability; (3) uncertainty in our future emissions; (4) uncertainty resulting from downscaling projections (Jenkins et al. 2010).

In this paper, we explore the applicability of different economic appraisal methodologies for livestock adaptation options, given the uncertainty surrounding climate impacts. We take recognised adaptation options available to the livestock sector and provide recommendations on which appraisal method is most appropriate given the characteristics of the options. To our knowledge, this classification of appraisal method to adaptation option has not previously been carried out and we believe it provides a useful summary of ways to approach adaptation appraisal in the livestock sector. Three detailed examples of appraisal methods to illustrate their potential application are provided. The focus is on farm decision-making within European livestock, but the principles can be applied to a range of production systems.

\section{Economic appraisal, risk and uncertainty}

The uncertainties described above make the application of decision-making approaches, at least in their 'basic' formulation, challenging. Standard cost-benefit analysis (CBA) attempts to maximise the benefits for society based on potential Pareto efficiency.

CBA assesses whether it is worthwhile implementing a project by comparing all its monetised costs and benefits expressed over a defined time span to obtain its net present value (NPV) (Eq. 1):

$(\operatorname{NPV}(i, N))=\sum_{t=0}^{N} \frac{R_{t}}{(1+i)^{t}}$

where $N$ is the total number of periods, $i$ the discount rate, $t$ is time and $R_{t}$ is the net cash flow (benefits minus costs) at time $t$. Where decisions are being made over short time frames or where there is reasonable certainty about the climate impacts, and the effect of the adaptation can be quantified, estimating the benefits of adaptation is relatively straightforward. A positive NPV indicates the project should generally proceed. Providing reliable data on costs and benefits are available, CBA can be carried out with limited technical resources and is accessible to a nontechnical audience. Other related methods to CBA are costeffectiveness analysis (CEA) or multi-criteria analysis (MCA) (Boardman et al. 2014; Triantaphyllou 2000).

Uncertainty in CBA (or CEA and MCA) can be addressed in different ways. For example, an expected values framework attaches subjective probabilities (Hallegatte et al. 2012), to evaluate the expected benefits as the probability-weighted average of the benefits based on how likely different states of the world are. Equation 2 can be modified as follows such that each mutually exclusive NPV is associated with a specific probability $p\left(R_{t}\right)$ :

$E(\operatorname{NPV}(i, N))=\sum_{t=0}^{N} p\left(R_{t}\right) \frac{R_{t}}{(1+i)^{t}}$

Probabilities can be based on past occurrences of events, expert knowledge or both. Subsequently projects matching the conditions of that future are designed and fine-tuned with sensitivity analysis. Additionally, scenarios of how the future might unfold (of equal likelihood) can be used (Boyd et al. 2006; García de Jalón et al. 2014); for CBA, 
this is a variant to include more than the central estimate as in the expected value framework. Worst and best cases that might be of particular interest in the context of climate change can be easily turned into scenarios. The theory of expected utility (Von Neumann 1967) allows for the inclusion of risk preferences in addition to contingent outcomes. The utility functions will differ depending on whether the decision-maker is risk-neutral, risk-loving or risk-averse.

All of these approaches have associated difficulties. Using several climate change scenarios provides the enduser with a range of possible outcomes, but with no attached probabilities making it difficult to make an informed decision. Expected values and utility can be used in situations of quantifiable uncertainty (and well-known risk preferences for expected utility). But for climate change we do not have a strong methodology to assess these subjective probabilities. They cannot be fully based on the past, because climate change is a new process for which we have no historical equivalent. Models share common flaws in their assumptions and their dispersion in results cannot be used to assess the real uncertainty (Hallegatte et al. 2012). The term deep uncertainty or severe uncertainty is used in such contexts and is characterised as a condition where decision-makers do not know or cannot agree upon a model that adequately describes cause and effect or its key parameters.

Uncertainty regarding future climate changes together with the imperative to make adaptation decisions in anticipation of these future climates can leave decisionmakers struggling to understand what the appropriate course of action might be, particularly with adaptation actions that require significant investment. Fortunately, many of the adaptations available to the agricultural sector do not involve long time horizons. Economic approaches based on expected values such as CBA and expected utility are generally suited for decision-making where probabilities can be attached to outcomes or changes are only implemented after the change has occurred. In the context of climate change, this will be particularly the case for short-term decision-making. Expected utility approaches are particularly useful to consider risk attitudes, specifically risk aversion, under increased weather variability which we expect to see more under climate change (IPCC 2012). But in some cases longer time horizons cannot be avoidedeither through the adaptation requiring a longer time to be fully effective (long lead time) or because once it has been adopted, it is difficult to reverse (long lifetime). In such contexts, CBA does not cope well and could lead to an inappropriate investment if the adaptation was unsuited for the actual climate outturn.

In both the academic and policy literature, alternative decision-making methods to appraise adaptation options are therefore being explored (Dessai and Hulme 2007; Dessai and van de Sluijs 2007; European Commission 2013a; Fankhauser et al. 1999; Hallegatte and CorfeeMorlot 2011; Lempert and Schlesinger 2000; Ranger et al. 2010; UNFCCC 2009; Watkiss et al. 2014). The focus is on so-called robust approaches. While all approaches that consider risk and uncertainty tackle the challenge of choosing actions in a future that cannot be predicted, robust approaches aim to better incorporate uncertainty by selecting projects that meet their purpose across a variety of plausible futures (Hallegatte et al. 2012). Here we identify three robust decision-making methods that would be applicable to appraisal in the agricultural sector.

Portfolio analysis (PA) combines several adaptation options in a portfolio to reduce risk by diversification (Markowitz 1952). Real options analysis (ROA) develops strategies that allow for learning and can be adjusted (e.g. upscaled or extended) when additional climate information becomes available. It originates from option trading in financial economics (Black and Scholes 1972; Cox et al. 2002; Dixit and Pindyck 1994; Merton 1973). Finally, robust decision-making (RDM) identifies how different strategies trade-off in order to identify options which might not be optimal under a specific climate outcome but less vulnerable under many climate outcomes (Lempert and Schlesinger 2000).

These techniques are particularly suited for adaptation options with long lead and/or lifetimes as they integrate uncertainty in the decision-making process. For a more detailed overview of robust approaches, see Dittrich et al. (2016) and Watkiss et al. (2014). In this paper, we focus on the identification of adaptation options and application of appropriate appraisal methods to the livestock sector. Possible adaptations are grouped by their lead and lifetime characteristics, in order to clarify the methodological approaches most appropriate for each option. The adaptation options considered were previously identified for European livestock agriculture in Wreford and Dittrich (2015) and are based on impact categories identified from the literature (Iglesias et al. 2012). Most of the decisionmaking for the adaptations covered in this paper would be autonomous adaptations made by private individuals (in these context livestock farmers). However, some of the options that require robust appraisal techniques may fall under the realm of planned public decision-making, such as large-scale water storage facilities or flood defence schemes.

\section{Short-lifetime adaptations}

Many of these adaptation options in the agricultural sector involve managerial changes, such as adjustments to the timing of operations, the movement of stock in response to 
immediate conditions, the management of feeding and grazing and disease and pest control. They also include soil and water management and conservation. The options are also often flexible and/or reversible, with few longer-term implications, such as changes to the grazing regime or the installation of small-scale water storage facilities. A comprehensive range of adaptation options are identified in Table 1 and their types of costs and benefits summarised so that the appropriate appraisal option can be recommended. Options with short lifetimes such as these managerial changes and options associated with small investments and when changes are reversible are generally suitable for appraisal by either (expected) formal or informal CBA. ${ }^{1}$ Because there is less long-term planning and economic evaluation required for these options, we spend the remainder of this article examining the appraisal methods appropriate for the long-lifetime or long-lead time adaptations.

\section{Long-lifetime adaptation: robust appraisal methods}

Other types of adaptations will require either a longer lead time in their planning, or will have long lifetimes, where the implications of decisions made now will be long-lived, and where uncertainty regarding the future climate can create a barrier to decision-making. These types of adaptations will often come under the realm of public decisionmaking and will require more robust appraisal approaches for efficient decision-making. In Table 1, we identify which of the three robust approaches discussed previously would be most suitable for a range of potential adaptation options in the livestock sector. We also include measures that would be made in response to increased weather variability, which may not necessarily have long lead times but address a range of future climates and hence require an appraisal method which takes the increased range of outcomes into account. The types of adaptations where portfolio analysis is most appropriate typically involve diversification of species (animal or crop). Adaptations that involve a large initial capital investment in the construction of a building or infrastructure are more suited for real options analysis, while RDM is ideal when a range of differentiated strategies for adaptation is available.

In Sects. 2.2.1 to 2.2.3, we take one adaptation example for each of the robust appraisal methods and describe in detail how the appraisal methods would be applied in practice.

\footnotetext{
${ }^{1}$ Many of these options would be appraised informally by the individual farmer without a quantitative appraisal; however, we can still expect the farmers to weigh up the (expected) costs and benefits of any action they take.
}

Adapting to heat stress: application of portfolio theory

All animals have a range of ambient environmental temperatures known as the thermal neutral zone and exceeding this range negatively affects livestock performance. Heat stress starts at the upper critical temperature of this zone. The animal cannot dissipate an adequate quantity of the heat to maintain the body's thermal balance (Moran et al. 2009). Heat stress causes productivity losses or even mortality and thus incurs economic costs to the industry. St-Pierre et al. (2003) estimated that total losses across animal classes averaged \$2.4 billion in the USA annually if there is no heat abatement.

Higher-yielding animals produce more body heat due to their greater metabolic activity (Settar et al. 1999; West et al. 2003), indicating a trade-off between productivity and heat tolerance (Hoffmann 2010). There is a general trend towards more productive animals to maximise profits, and we may thus expect heat stress to become more of a problem in future due to both climate change and trends in breeding. While this trade-off between productivity and heat tolerance can apply to a range of livestock species, we focus here on dairy cattle due to data availability.

We suggest the application of PA to appraise adaptations to combat heat stress in livestock. In the context of climate change adaptation, PA has been applied to choosing wetland habitats in different locations (Ando and Mallory 2012), and to the regeneration of forests with different tree seeds (Crowe and Parker 2008). Our approach to address heat stress in livestock is to diversify the breeds in a particular herd to reduce the risk of heat stress while trading off some productivity. Having a number of high-productivity animals in the herd with low heat tolerance levels and a number of lower-productivity animals with high heat tolerance will achieve this objective. It should be noted that this is not an adaptation to long-term temperature changes (as the productive lifetime of a dairy cow usually does not exceed 5 years); rather, it is an adaptation to increased variability in climate due to climate change.

The adaptation choice (breed composition) is determined by maximising benefits (measured through a productivity metric such as milk yield) given the decisionmaker's risk affinity. Alternatively, given a defined benefit of the adaptation options, risk is minimised across all adaptation options. Equation 3 specifies an example minimisation problem of the latter type taken from Ando and Mallory (2012).

Min $w^{T} \sum w$, subject to $\sum_{i} w_{i}=1, w_{i}>0$
$\quad$ for all $i$, and $E[R] w=\mu$ 
Table 1 Adaptation options and the identification of their relevant costs and benefits as well as of a suited appraisal method

Type of Types of adaptations Further explanation
appraisal

CBA Move herds to more suitable conditions from waterlogged fields, extreme dry situations and extreme heat or cold

Change breeding and shearing patterns. For animals kept outside, e.g. sheep, the time of lambing and shearing can be adapted to the seasonal weather conditions

Adjust stocking density to avoid poaching and overgrazing; to cope with a reduction in available food; to minimise disease outbreaks; to cope with heat stress in intensive conditions (e.g. transport)

Ensure access to water to aid thermoregulation

Adjust timing of animal transport to avoid heat/cold exposure

Adjust diet to ensure sufficient dealing with hot weather. Ensure energy requirements are being met if the heat reduces total feed intake; supplements can also assist

Vaccination for climate-related diseases

Conserving surplus production of feed supply. Seasonal variations in roughage feed supply are buffered by conservation methods

Supplemental feeding in situations of a loss in forage quality and quantity

Restoring degraded land to increase agricultural output or counteract decreases in output in other areas

Apply crop/fallow rotation

Optimal use of fertilisers and manure

CBA Set clear water use priorities. Ensuring the most important water demands are covered such as drinking water for animals and basic irrigation for crops

Increase water use efficiency

Reduced/zero tillage in order not to disrupt the soil

Improve field drainage water absorption capacity to minimise waterlogging

Small-scale reservoirs on farmland to collect rainwater and technical improvements in irrigation equipment

Reduce run-off through contoured hedgerows and buffers

Use of precision agriculture techniques

Insurance

Water management practices. Terraces, mulching, ditches and grass strips can be used to conserve soil water. Timing of water use such as irrigation at night, water efficiency and conservation strategies through separating dirty/clean water can be adjusted

Incorporation of crop residues
Benefits include maintained productivity; costs include management and labour (if no shelter exists, long-term adaptation will be to construct more housing; see options for robust appraisal)

Benefits include maintained productivity (e.g. through avoidance of heat/cold stress); costs include labour

Benefits include pasture preservation; avoided costs of disease outbreaks; maintained productivity (per animal); costs include reduced total production

Benefits include maintained productivity; costs include management/ labour costs

Benefits include maintained productivity and avoided mortality; costs include management/labour costs

Benefits include maintained productivity/reduced mortality; costs include cost of feed/supplements, labour

Benefits include maintained productivity/reduced mortality; costs include labour; purchase of vaccines

Benefits include continued production; costs include foregone income from sale of surplus feed

Benefits include maintained productivity/reduced mortality; costs include purchase of supplemental feed

Benefits include increased output; costs include initial investment and ongoing maintenance, loss of output where this involves leaving the land fallow

Benefits include increased soil fertility and yield due to $\mathrm{N}$ fixing in soils in the medium/long term and also improved water holding capacity, thus reducing drought and pest outbreaks. Costs include management changes

Benefits include improved productivity and potential increased resilience to climate change; costs may include increased fertiliser costs (potentially also indirect costs of increased GHG emissions)

Benefits include avoided costs of purchasing water; or implications of stock and crop dehydration. Costs include foregone profit from lower prioritised uses

Benefits include avoided costs of purchasing water; or implications of stock and crop dehydration. Costs include foregone profit from lower prioritised uses

Benefits include higher yields due to improved soil fertility and water retention. Costs include the loss of crop residues for animal feed

Benefits include avoided soil compaction and stock health costs; negative crop impacts. Costs include machinery and maintenance

Benefits include production continuity; costs include installation, maintenance and potential foregone profit from land taken out of production

Benefits include avoided erosion and the costs of planting of and more difficult field access due to hedgerows/buffers

Benefits include improved efficiency; costs can include machinery and equipment

Benefits include avoided expected financial loss; costs include premiums

Benefits include avoided costs of purchasing water; or implications of stock and crop dehydration. Costs include machinery, maintenance and labour

Benefits include soil fertility and water retention through building organic matter. Difficult to quantify due to the long-term nature of changing soil C. Costs include the loss of crop residues for animal feed; labour and machinery 
Table 1 continued

\begin{tabular}{|c|c|c|}
\hline $\begin{array}{l}\text { Type of } \\
\text { appraisal }\end{array}$ & Types of adaptations & Further explanation \\
\hline & Additional weed/pest control & $\begin{array}{l}\text { Benefits include avoided weed and pest outbreaks; costs include weed } \\
\text { and pest control products; labour; indirect costs of increased nutrient } \\
\text { leakage, pesticide resistance }\end{array}$ \\
\hline & Shelter belts & $\begin{array}{l}\text { Benefits include shade and protection from wind, potentially increased } \\
\text { yield and decreased erosion. Costs include more difficult access to } \\
\text { fields, labour, equipment, maintenance and potentially foregone profit } \\
\text { from land taken out of production }\end{array}$ \\
\hline & Advisory service for farmers & $\begin{array}{l}\text { Benefits include increased adoption of these measures and thus avoided } \\
\text { losses and maintained production of the sector. Costs include the } \\
\text { administrative costs of establishing advisory services (although } \\
\text { existing services may be able to incorporate adaptation advice), } \\
\text { labour }\end{array}$ \\
\hline \multirow[t]{5}{*}{$\begin{array}{l}\text { Portfolio } \\
\text { analysis }\end{array}$} & $\begin{array}{l}\text { Changing high-yield/high-productive breeds for lower- } \\
\text { yielding/less productive more heat-tolerant breeds of cows/ } \\
\text { sheet }\end{array}$ & $\begin{array}{l}\text { Heat tolerance/productivity can be traded off through a 'basket' of } \\
\text { breeds }\end{array}$ \\
\hline & $\begin{array}{l}\text { Cover crops to improve soil structure and to reduce erosion } \\
\text { due to wind and rainfall }\end{array}$ & $\begin{array}{l}\text { Cover crops can be sown on some fields and not on others depending on } \\
\text { the cost for cover crops and time available to sow, i.e. a basket of } \\
\text { cover crops. This is not a long-term adaptation option but can help to } \\
\text { improve soil structure in a given climate more efficiently }\end{array}$ \\
\hline & $\begin{array}{l}\text { Grass and legumes can be combined in a way to trade-off } \\
\text { productivity and heat tolerance }\end{array}$ & $\begin{array}{l}\text { Grass-legume swards have important yield advantages compared to } \\
\text { monocultures. Legume species have higher temperature optima than } \\
\text { grasses. Other potential benefits: On soil structure due to deep rooting } \\
\text { systems and for carbon sequestration (the latter is partially dependent } \\
\text { on the change in reseeding that may be required). Improvement of } \\
\text { productivity on crops/grasslands through more efficient fertiliser use } \\
\text { due to reduced requirement for } \mathrm{N} \text { by the legumes }\end{array}$ \\
\hline & $\begin{array}{l}\text { Replace/combine high-productivity crop varieties with more } \\
\text { pest-resistant varieties }\end{array}$ & \\
\hline & $\begin{array}{l}\text { On a regional/national level: portfolio of pastures and crops } \\
\text { according to land capability }\end{array}$ & \\
\hline \multirow[t]{4}{*}{$\begin{array}{l}\text { Real options } \\
\text { analysis }\end{array}$} & $\begin{array}{l}\text { Hard flood risk defences to protect livestock and agricultural } \\
\text { land }\end{array}$ & $\begin{array}{l}\text { The defences can be scaled up over time in the least costly way if the } \\
\text { potential full design is considered now }\end{array}$ \\
\hline & $\begin{array}{l}\text { Natural flood risk management (NFM) measures to protect } \\
\text { livestock and agricultural land }\end{array}$ & $\begin{array}{l}\text { The defences can be scaled up over time in the least costly way if the } \\
\text { potential full design is considered now }\end{array}$ \\
\hline & Housing to protect animals from heat & $\begin{array}{l}\text { The possibility of later adding cooling pads, fans systems, water sprays/ } \\
\text { misters to buildings and/or outdoor areas (e.g. collecting yards) }\end{array}$ \\
\hline & $\begin{array}{l}\text { Large-scale irrigation for improved water supply/farm scale } \\
\text { reservoirs }\end{array}$ & $\begin{array}{l}\text { Can be scaled up over time in the least costly way if the potential full } \\
\text { design is considered now }\end{array}$ \\
\hline $\begin{array}{l}\text { Robust } \\
\text { decision- } \\
\text { making }\end{array}$ & $\begin{array}{l}\text { Holistic water basin management in a region to identify the } \\
\text { least vulnerable strategies to meet the water demand }\end{array}$ & $\begin{array}{l}\text { Water flow related to climate change scenarios as well as benefits/costs } \\
\text { of the options under climate change }\end{array}$ \\
\hline
\end{tabular}

where $w_{i}$ are the weights of the portfolio of breeds, $T$ is the transpose operator, $\Sigma$ is the covariance matrix of $R, E[R]$ is the expected return (milk yield or price per litre milk) of each breeds and $\mu$ is the target expected return. A higher return is associated with a higher risk. A portfolio is best balanced if the co-variances of the assets are negative, off setting the risk under different scenarios. In other words, low return on one asset will be partly offset by higher returns from other assets during the same period. This applies directly in the livestock case. The higher the productivity of an animal, the lower the heat tolerance, and vice versa. The challenge is to relate the climate change scenarios directly to heat stress and thus to return. Using
UKCIP02 data (probabilistic climate data for the UK), Moran et al. (2009) calculated the maximum temperature humidity index (THI) [i.e. the relationship between temperature, humidity and heat stress (Wiersma 1990)] under different climate change scenarios using maximum monthly temperatures. Each class of animal was assigned a THI threshold based on empirical studies above which that class of animal begins to suffer from heat stress. Subsequently, the data can be related to milk loss in kilograms per day, and based on the number of days where the threshold is exceeded, milk loss per year can be calculated. The return (milk yield) for each breed can then be calculated under each climate change scenario. Average expected returns then need to be calculated across all 
chosen climate change scenarios by attaching probabilities to the scenarios. This is also a possible short-coming of the method as it is not clear that probabilities can be attached with confidence to climate change outcomes (Hallegatte et al. 2012). PA makes the implicit assumption that climate change uncertainty can be quantified through expected values. Further data that are required include the co-variances between the returns of the different breeds. Given these data, the problem can be solved either as a minimisation or a maximisation problem with a constraint. For Eq. 3, risk is minimised (based on the co-variances of the assets) for a given return. A so-called efficiency frontier can be derived as shown in Fig. 1 if the minimisation problem is solved for a range of target returns. The efficiency frontier identifies different portfolios for the number of dairy cows that should be purchased proportionally as part of the herd (i.e. the portfolio weights). PA assumes that the decision-maker is risk-averse and the choice of a specific portfolio on the efficiency frontier depends on his/ her risk tastes (i.e. their type of utility function). Thus, for example, under increased weather variability, a more riskaverse farmer may opt for a portfolio with an overall lower expected return but relatively low risk, i.e. a point in the left bottom corner on the efficiency frontier in Fig. 1.

\section{Adapting to flood risk: applying real options analysis}

The frequency and intensity of extreme events is likely to increase as a result of climate change (Schär et al. 2004; Stott et al. 2016). Flooding can pose a threat to livestock in two ways: first, directly by threatening the safety of animals, in both housed or fields, and second, indirectly by damaging forage in the form of pastures and crops used to feed livestock, and damages to farm buildings, machinery and other assets. As a consequence, additional forage may need to be bought in by the farmer and assets repaired at potentially high cost. In automated systems, waste

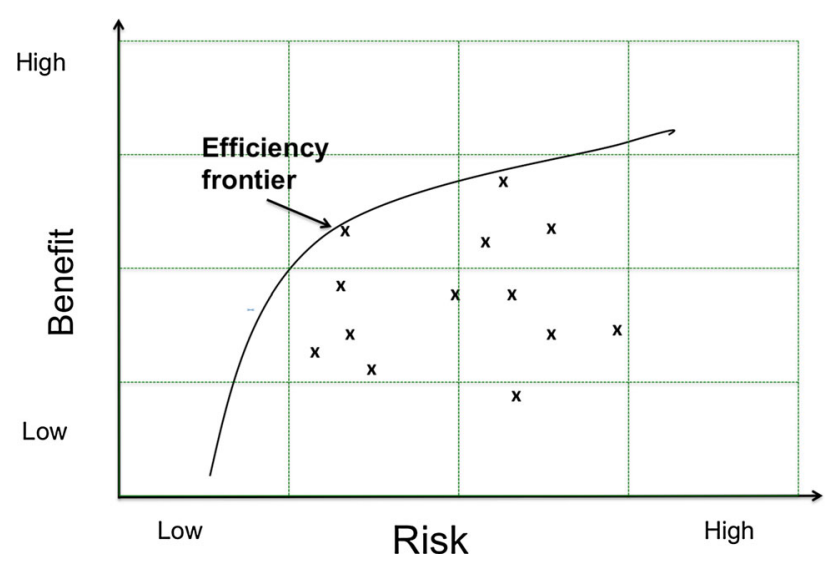

Fig. 1 Graphical representation of different feasible portfolios management systems can be damaged leading to increased exposure to pathogens and risk of disease or threaten water quality (Schmidt 2000). In monetary terms, storms and floods are already the most frequent and costly weatherrelated disasters in Europe and accounted for $77 \%$ of the economic losses caused by extreme weather events between 1980 and 2006 (CEA 2007).

Building flood risk mitigation measures can help to alleviate this problem. The measures can be both standard 'hard' engineering solutions such as flood walls but also natural flood management (NFM) measures such as afforestation along streams, rivers and field edges to slow down peak flow, restoration of flood plains and retention ponds for water. Hard engineering solutions and to an extent soft NFM measures involve long-lived decisions with high sunk costs that are likely to be sensitive to climate change uncertainties.

If the frequency of floods changes substantially, i.e. a flood that occurs in the current climate on average every 50 years may occur in the future on average every 35 years, flood mitigation measures can prevent severe damage and associated costs. Uncertainty about the future means farmers may be unsure whether to invest in building flood risk mitigation measures, and risk over-adapting if extreme events do not change sufficiently in frequency to justify the action. In this situation, a ROA may enable a more informed decision.

ROA handles deep uncertainty by allowing for learning about climate change over time. The intuitive argument is to postpone costly (partly irreversible) measures until more scientific evidence on the impacts of climate change is gathered. Uncertainty is assumed to resolve with the passage of time due to increasing knowledge on climate change impacts (Hallegatte 2009; Watkiss et al. 2014). In the context of flood adaptation measures, this means starting out with a relatively small flood adaptation measure and scaling it up over time if necessary. However, there is a trade-off as additional investment comes with fixed cost; therefore, continuous investment is not the most economically efficient solution either (Van Dantzig 1956).

Applications of ROA to climate change include investment in coastal protection (Linquiti and Vonortas 2012; Scandizzo 2011; Woodward et al. 2014). Gersonius et al. (2013) determined the adjustable design of an urban drainage system in West Garforth, England, that minimises the lifetime cost of the system and Dittrich et al. (Dittrich 2016) examined the application of ROA to afforestation as a flood management measure.

For a ROA model that can either minimise costs (as an extension of cost-effectiveness analysis) or maximise benefits (as an extension of cost-benefit analysis), the following steps need to be carried out. Note that the specific 
solution will vary depending on the problem at hand. ROA also assumes risk neutrality such as CBA and CEA but extends both by adding the option of learning instead of having to make a now or never decision.

In a first step, climate scenarios for the area in question are required, specifically rainfall data. The UK Met office (Murphy et al. 2009), for example, provides a dataset with historical rainfall data across the UK which is perturbed for a range of climate change scenarios. These data need to be further processed as transition probabilities need to be assigned to different plausible climate change paths. Obtaining such transition probabilities for different time paths can prove challenging such as for PA as this requires attaching probabilities to climate change scenarios and subsequently probabilities on how to move from one climate change path to another. In some studies (Gersonius et al. 2013; Linquiti and Vonortas 2012), the probabilities have been be obtained with the same formula as in the financial option model which is based on the assumption that the logarithm of the underlying uncertain parameter, here rainfall, follows a stochastic process called geometric Brownian motion (GBM) (see Cox et al. (2002) for an overview). Moving window processes have also been applied (van Der Pol et al. 2015). In a next step, the climate data need to be linked to a hydrological model. The exact hydrological data needed will depend on the specific question and the level of hydrological detail that is required. For a costeffectiveness application, a constraint such as a specific flood protection standard may be defined. For a costbenefit analysis, a damage module needs to be included. At a minimum, the model needs to measure discharge without the flood mitigation measure and with different implementations of the mitigation measure under different peak flows. The aim is to relate different levels of peak flow to different levels of discharge subject to different levels of implementation of the flood mitigation measure. In a subsequent step, the economic optimisation model is added. Costs comprise the design, land, construction and maintenance costs of which some are incurred in the present time period, and others are delayed or avoided altogether. Maintenance costs depend on the specific flood mitigation measure. Benefits are avoided damages. Finally, the decision on when to exercise the option to scale up the flood mitigation measure must be made. The decision criteria can be tailored to the requirements of the problem, for example, once certain damage has been exceeded with a certain probability, or once a predefined standard (e.g. avoid 1 in 10 flood) cannot be guaranteed anymore.

Equation 4 presents an example of a cost-effectiveness problem set up as a Bellman equation which is solved recursively (van Der Pol et al. 2015).
$J_{t}(\varphi, x)=\min z \frac{\left(\frac{I(z)+O(x+z)}{(1+\delta)^{t}}+E\left\{J_{t+1}\left(\left(\varphi_{t+1} \mid \varphi\right), x+z\right)\right\}\right)}{\text { s.t. } R(f, x+z) \geq \alpha}$

where $J_{t}$ is the value function, $x$ the stock variable of the system element, $z$ the additional investment at each time step and $\varphi$ describes distribution of the uncertain parameter today and in the next time period. The cost function depends on the investment cost $I$, the maintenance cost $O$ and the discount rate $\delta$. Finally, this is subject to a reliability constraint $R$ which depends on $x+z$ and $\mathrm{f}$ the distribution of specific rainfall events, and $\alpha$ the predefined reliability standard.

ROA does not result in a single highest ranked option as an output. It provides flexible strategies along the different climate paths that can be adjusted over time and an explicit valuation of created and destroyed capabilities. The present value of the total costs of the RO mitigation measure must be less than or equal to the present value of the total costs of the non-flexible mitigation measure (NRO) (if they are not then there is no benefit to the adjustable mitigation measure and a large flood mitigation measure should be installed from the outset).

To provide quantitative results, good data are necessary: methods such as genetic algorithms or dynamic programming that usually require expert knowledge can provide solutions to the objective function. However, ROA can also be applied qualitatively by drawing up a decision tree that outlines different adaptation paths to provide conceptual guidance on the adaptation strategy.

\section{Water management: application of robust decision-making}

In some cases, farm-level adaptation in the livestock sector requires integration with a wider set of policies. This may be the case in a region suffering from water scarcity where a holistic water management approach is needed. Water may be needed for irrigation of fields, drinking water for animals, as well as for household use. Meeting the demands of all stakeholders under such conditions can be extremely challenging even without the changes in future water availability resulting from climate change. An adaptation appraisal method that works well in such situations is RDM. The concept of RDM is not new (Matalas and Fiering 1977) and has been used in different variations, but it is most prominently linked to the RAND Corporation (Lempert et al. 2003). It was originally designed for decision-making in poorly characterised uncertainty with a subsequent application to climate change adaptation (Lempert et al. 2006).

RDM can help to structure a complex decision-making process with a large set of options. It helps to understand the 
potential consequences of strategies over many scenarios. Lempert and Groves (2010) applied RDM to determine water management strategies in the western USA in the context of climate change. The study tested the current water management plan which aims to ensure sufficient and affordable water supply considering that precipitation and temperature patterns might change significantly in the long term. Besides a wide range of climate change scenarios, further uncertainties considered included future socioeconomic conditions and the agency's ability to implement the plan. Further applications include a set of coastal risk reduction and restoration projects in Louisiana, USA, given a budget constraint (Groves and Sharon 2013). In an application to flood risk management in Ho Chi Minh City's Nhieu Loc-Thi Nghe canal catchment, Lempert et al. (2013) evaluated that the current infrastructure plan may not be the most robust strategy in many plausible futures emphasising the importance of adaptively using retreat measures.

RDM determines less vulnerable strategies by identifying measures that have little sensitivity to different climate change scenarios by trading off some optimality (Lempert and Collins 2007). Figure 2 illustrates the decision-making process of RDM.

In general, RDM models will strongly depend on the adaptation problem analysed. If needed, the analysis can be simplified according to the decision-makers' needs by reducing the range of climate scenarios and other uncertainties considered as well as the number of strategies.

In a first step, the aim of the decision-making process and a number of potential strategies need to be defined. Ideally, the potential strategies must be sufficiently differentiated to allow for a meaningful comparison of tradeoffs. For water demand, this may be a certain supply to all parties involved over a specific time period and how this

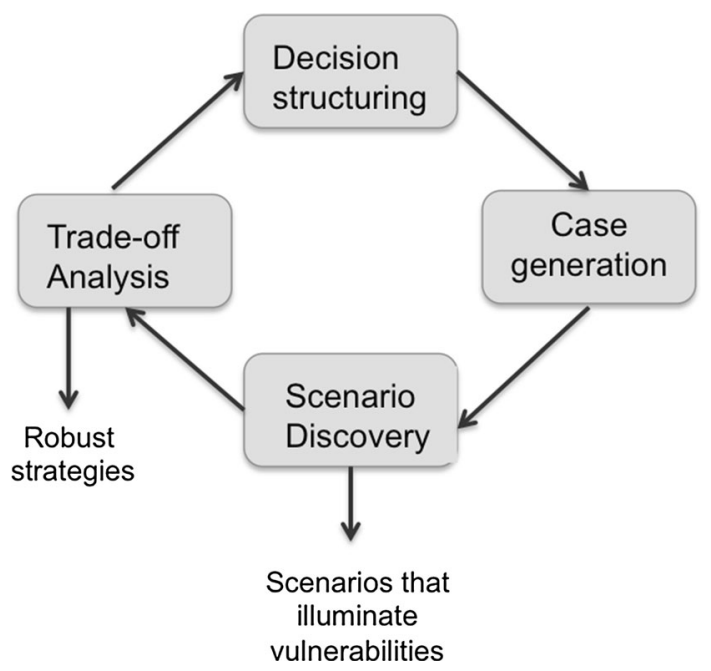

Fig. 2 Decision-making steps: robust decision-making (Lempert et al. 2013) might be accomplished, for example, through irrigation measures, water conservation devices, reduction in water leaks, local water consumption audits. The second step includes identifying uncertain parameters and their plausible ranges including climate change impacts, future water demand and others. This is a crucial task, as it will define the vulnerability of different strategies. Values may be obtained from the literature, expert opinion elicitation or stakeholder consultation. The choice and range of these parameters is determined by the decision-maker, introducing unavoidable subjectivity. RDM applied fully quantitatively is very data and resource intensive, but to avoid overly complex outcomes it may be advisable to limit the number of uncertainties. For the uncertainty concerning climate change, simulation models are used to create large ensembles (thousands or millions of runs) of multiple plausible future scenarios from the parameters without assuming a likelihood of the different scenarios. A simplified version will use fewer model runs, however, at the cost of potentially ignoring the least vulnerable option.

In a third step, costs and benefits of different measures are assessed. This includes hydrological modelling for the area of interest in order to predict changes in flows under different climate change scenarios as well as demand models for agricultural and potentially household water demand. Subsequently, the different strategies are tested against a robustness criterion, which may be that the strategy performs well compared with alternative strategies in many different future scenarios or a certain cost-benefit measure (Lempert 2014). In an iterative process, the candidate strategies can be adjusted and fed repeatedly through the ensembles. Accordingly, RDM does not predict uncertainty and then rank alternative strategies, but characterises uncertainty in the context of a specific decision: the most important combinations of uncertainties to the choice among alternative options are determined in different plausible futures. As a result of the analysis, tradeoff curves compare alternative strategies rather than providing any conclusive and unique ordering of options. Generally, a strategy that performs well over a range of plausible futures might be chosen over a strategy that performs optimally under expected conditions.

\section{Discussion and conclusion}

We assert in this paper that the lead time (and linked to this reversibility) and lifetime of an adaptation action determine the appropriate method of economic appraisal for decisionmaking. Adaptations that can take effect relatively instantaneously can wait until the climate is observed to have changed, and can be reversed if they are no longer appropriate (although farmers will likely be observing 
trends and planning ahead before they take action). These types of adaptations can be appraised through (expected) formal or informal CBA.

It should also be noted that despite the short lead and lifetime of many options, farmers will not know the consequences of their actions with certainty in particular where there is increased weather variability under climate change. In such contexts, the use of expected utility theory with the inclusion of risk coefficients and PA can prove useful as a way to guide decision-making.

The choice of which robust decision-making method to apply for options with a longer lead/lifetime will very much depend on the characteristic of the adaptation problem, its adaptation options, as well as the objectives of the decision-maker. ROA can assist in identifying the value of flexible adaptation strategies where the adaptation options can be scaled up/extended. RDM is suited to determining the less vulnerable strategies for a complex adaptation problem, and finally PA can be used to identify the most efficient combination of options that work well across scenarios. We provided one potential application for each robust method; however, some of the adaptation options we describe (and which are given in Table 1) could also be appraised with another method. For example, RDM would also be suited to analyse the costs and benefits of a largescale flood defence measure if it affects multiple stakeholders and suffers from poorly characterised uncertainty. Similarly, a standard expected utility approach could also be used when assessing the construction of defensive infrastructures; however, the information yielded from this versus a ROA approach may not be as useful as it would assume a now or never decision about the investment rather than allowing for adjustments over time. Yet if it were not feasible to design the flood defence measure in a flexible way (and the uncertainty is well characterised), an expected utility may be sufficient. Indeed, in many cases, the decision which approach to use will be determined by trade-offs between the approaches.

Proper application of these techniques may, however, be very data intensive and requires specialist skills that may not be available to all decision-makers. Over time decisionmakers will become more familiar with the principles, the methods may become more mainstream, and concurrently academics should work towards making the full analysis more accessible. This includes user-friendly specific software or spreadsheets where practitioners could enter their specific data and requirements and the programme would provide the output. Examples of simplified applications include the TE2100 project (Reeder and Ranger 2010) for ROA and Frontier Economics (2013) evaluated natural flood risk measures in North Yorkshire, UK, using simplified RDM by reducing the number of climate change scenarios included. Matrosov et al. (2013) used RDM to select portfolios of water supply and demand strategies in the Thames water system, UK, simplifying the methodology by considering a smaller number of options but considering a detailed assessment of the different uncertainties (climate change through hydrological flows as well as demand and energy prices). Over time as decision-makers become more familiar with the principles, the methods may become more mainstream, and concurrently academics should work towards making the full analysis more accessible as well-such as user-friendly specific software or spreadsheets where practitioners could enter their specific data and requirements and the programme would provide the output.

It should be noted that the adaptations here are incremental rather than transformative, intended to avoid disruptions of the current systems (Kates et al. 2012). In some locations, this will not be sufficient due to high risk and vulnerability. Such transformation requires not only feasible adaptation options but also appropriate social and institutional contexts (Kates et al. 2012). In the European livestock sector, we may speculate that such options include changing the type of agricultural activity (e.g. from crops to livestock) or even abandoning agriculture as an income source in certain areas on the supply side (Howden et al. 2007). On the demand side, this may include attempts to reduce meat consumption (which also benefits mitigation) (Ripple et al. 2014). The latter point shows that climate change will not necessarily be the main driver of decision-making, other factors such as market risk and policy changes will prove influential.

Open Access This article is distributed under the terms of the Creative Commons Attribution 4.0 International License (http://crea tivecommons.org/licenses/by/4.0/), which permits unrestricted use, distribution, and reproduction in any medium, provided you give appropriate credit to the original author(s) and the source, provide a link to the Creative Commons license, and indicate if changes were made.

\section{References}

Ando AW, Mallory ML (2012) Optimal portfolio design to reduce climate-related conservation uncertainty in the Prairie Pothole Region. Proc Natl Acad Sci USA 109:6484-6489. doi:10.1073/ pnas. 1114653109

Black F, Scholes M (1972) The valuation of option contracts and a test of market efficiency. J Finance 27:399-417

Boardman A, Greenberg D, Vining A, Weimer D (2014) Cost-benefit analysis. Concepts and practice, 4th edn. Pearson Education Limited, Essex

Boyd R, Wade S, Walton H (2006) Climate change impacts and adaptation: cross regional research project (E). DEFRA, London, England

CEA (2007) Reducing the social and economic impact of climate change and natural catastrophes: insurance solutions and public private partnerships. Insurers of Europe, Brussels, Belgium 
Cox JC, Ross SA, Rubinstein M (2002) Option pricing: a simplified approach. In: Gallagher LA, Taylor MP (eds) Speculation and financial markets. Volume 2. Elgar Reference Collection, International Library of Critical Writings in Economics, Cheltenham/Northampton, pp 461-495

Crowe K, Parker W (2008) Using portfolio theory to guide reforestation and restoration under climate change scenarios. Clim Change 89:355-370. doi:10.1007/s10584-007-9373-x

Dessai S, Hulme M (2007) Assessing the robustness of adaptation decisions to climate change uncertainties: a case study on water resources management in the East of England. Glob Environ Change. doi:10.1016/j.gloenvcha.2006.11.005

Dessai S, van de Sluijs J (2007) Uncertainty and climate change adaptation a scoping study. Copernicus Institute for Sustainable Development and Innovation, Utrecht

Dittrich R (2016) Top-down and bottom-up decision-making for climate change adaptation. An application to flooding. Thesis $(\mathrm{PhD})$, School of Geosciences, University of Edinburgh, Edinburgh, Scotland

Dittrich R, Wreford A, Moran D (2016) A survey of decision-making approaches for climate change adaptation: are robust methods the way forward? Ecol Econ 122:79. doi:10.1016/j.ecolecon. 2015.12.006

Dixit AK, Pindyck RS (1994) Investment under uncertainty. Princeton University Press, Princeton

European Commission (2013a) EU adaptation strategy. http://ec. europa.eu/clima/policies/adaptation/what/documentation_en.htm

European Commission (2013b) How many people work in agriculture in the European Union? An answer based on Eurostat data sources. EU Agricultural Economics Briefs, no. 8, July 2013. European Commission, Brussels

Fankhauser S, Smith JB, Tol RSJ (1999) Weathering climate change: some simple rules to guide adaptation decisions. Ecol Econ 30:67-78. doi:10.1016/S0921-8009(98)00117-7

FEFAF (2013) Feed \& food. Statistical yearbook 2013. http://www. fefac.eu/files/57916.pdf. Accessed 4 May 2015

García de Jalón S, Iglesias A, Cunningham R, Pérez Díaz JI (2014) Building resilience to water scarcity in southern Spain: a case study of rice farming in Doñana protected wetlands. Reg Environ Change 14:1229-1242

Gersonius B, Ashley R, Pathirana A, Zevenbergen C (2013) Climate change uncertainty: building flexibility into water and flood risk infrastructure. Clim Change 116:411-423. doi:10.1007/s10584012-0494-5

Groves DG, Sharon C (2013) Planning tool to support planning the future of coastal Louisiana. J Coastal Res. doi:10.2112/SI_67_10

Hallegatte S (2009) Strategies to adapt to an uncertain climate change. Global Environ Change Part A Hum Policy Dimens 19:240-247. doi:10.1016/j.gloenvcha.2008.12.003

Hallegatte S, Corfee-Morlot J (2011) Understanding climate change impacts, vulnerability and adaptation at city scale: an introduction. Clim Change 104:1-12. doi:10.1007/s10584-010-9981-8

Hallegatte S, Shah A, Lempert R, Brown C, Gill S (2012) Investment decision making under deep uncertainty-application to climate change. The World Bank, Policy Research working paper series: 6193

Hoffmann I (2010) Climate change and the characterization, breeding and conservation of animal genetic resources. Anim Genet 41(Suppl 1):32-46. doi:10.1111/j.1365-2052.2010.02043.x

Hoving IE, Stienezen MWJ, Hiemstra SJ, van Dooren HJ, de Buisonjé FE (2014) Adaptation of livestock systems to climate change; functions of grassland, breeding, health and housing. Livestock research report 793. Wageningen UR Livestock Research, Wageningen

Howden SM, Soussana J-F, Tubiello FN, Chhetri N, Dunlop M, Meinke H (2007) Adapting agriculture to climate change. Proc Natl Acad Sci USA. doi:10.2307/25450777
Iglesias A, Quiroga S, Moneo M, Garrote L (2012) From climate change impacts to the development of adaptation strategies: challenges for agriculture in Europe. Clim Change 112:143-168. doi:10.1007/s10584-011-0344-x

IPCC (2012) Summary for Policymakers. In: Managing the Risks of Extreme Events and Disasters to Advance Climate Change Adaptation In: Field CB, Barros V, Stocker TF, Qin D, Dokken DJ, Ebi KL, Mastrandrea MD, Mach KJ, Plattner G-K, Allen SK, Tignor M, Midgley PM (eds) A Special Report of Working Groups I and II of the Intergovernmental Panel on Climate Change. Cambridge University Press, Cambridge, UK, New York, NY, USA, pp. 3-21

Jenkins G, Murphy J, Sexton D, Lowe J, Jones P, Kilsby C (2010) UK climate projections: briefing report. Version 2, December 2010. MetOffice Hadley Center, Exeter

Kates RW, Travis WR, Wilbanks TJ (2012) Transformational adaptation when incremental adaptations to climate change are insufficient. Proc Natl Acad Sci USA. doi:10.1073/pnas. 1115521109

Kovats RS, Valentini R, Bouwer LM, Georgopoulou E, Jacob D, Martin E, Rounsevell M, Soussana J-F (2014) Europe. In: Barros VR, Field CB, Dokken DJ, Mastrandrea MD, Mach KJ, Bilir TE, Chatterjee M, Ebi KL, Estrada YO, Genova RC, Girma B, Kissel ES, Levy AN, MacCracken S, Mastrandrea PR, White LL (eds) Climate change 2014: impacts, adaptation, and vulnerability. Part B: regional aspects. Contribution of Working Group II to the fifth assessment report of the Intergovernmental Panel on Climate Change. Cambridge University Press, Cambridge, United Kingdom and New York, NY, USA, pp 1267-1326

Lempert RJ (2014) Embedding (some) benefit-cost concepts into decision support processes with deep uncertainty. J Benefit Cost Anal 5:487-514

Lempert RJ, Collins MT (2007) Managing the risk of uncertain threshold responses: comparison of robust, optimum, and precautionary approaches. Risk Anal 27:1009-1026. doi:10. 1111/j.1539-6924.2007.00940.x

Lempert RJ, Groves DG (2010) Identifying and evaluating robust adaptive policy responses to climate change for water management agencies in the American west. Technol Forecast Soc Chang 77:960-974

Lempert R, Schlesinger M (2000) Robust strategies for abating climate change. Clim Change 45:387-401. doi:10.1023/A: 1005698407365

Lempert RJ, Popper SW, Bankes SC (2003) Shaping the next one hundred years. New methods for quantitative, long-term policy analysis. RAND Publications, Santa Monica, California

Lempert RJ, Groves DG, Popper SW, Bankes SC (2006) A general, analytic method for generating robust strategies and narrative scenarios. Manag Sci. doi:10.2307/20110530

Lempert R, Kalra N, Peyraud S, Mao Z, Tan SB, Cira D, Lotsch A (2013) Ensuring robust flood risk management in Ho Chi Minh city. The World Bank, Policy Research working paper series: 6465

Linquiti P, Vonortas N (2012) The value of flexibility in adapting to climate change: a real options analysis of investments in coastal defense. Clim Change Econ 3:1-33. doi:10.1142/S20100078 $1250008 \mathrm{X}$

Markowitz H (1952) Portfolio selection. J Finance. doi:10.2307/ 2975974

Matalas NC, Fiering MB (1977) Water resource systems planning. National Academy of Sciences, Washington

Matrosov E, Padula S, Harou J (2013) Selecting portfolios of water supply and demand management strategies under uncertaintycontrasting economic optimisation and 'robust decision making' approaches. Water Resour Manage 27:1123-1148. doi:10.1007/ s11269-012-0118-x 
Mendelsohn R, Nordaus WD (1994) The impact of global warming on agriculture: a Ricardian analysis. Am Econ Rev 84:753-771

Merton RC (1973) Theory of rational option pricing. Bell J Econ Manag Sci 4:141-183. doi:10.2307/3003143

Moran D, Topp K, Wall E, Wreford A (2009) Climate change impacts on the livestock sector. Draft final report AC0307, SAC Research, Edinburgh, Scotland

Murphy JM, Sexton DMH, Jenkins GJ, Booth BBB, Brown CC, Clark RT, Collins M, Harris GR, Kendon EJ, Betts RA, Brown SJ, Humphrey KA, McCarthy MP, McDonald RE, Stephens A, Wallace C, Warren R, Wilby R, Wood RA (2009) UK climate projections science report: climate change projections. Exeter, UK, Meteorological Office Hadley Centre, pp 192

Ranger N, Antony M, Dietz S, Frankhauser S, Lopez A, Ruta G (2010) Adaptation in the UK: a decision-making process. Environment Agency 2010-09

Reeder T, Ranger N (2010) How do you adapt in an uncertain world? Lessons from the Thames Estuary 2100 project. World Resources Report, Washington

Renaudeau D, Collin A, Yahav S, de Basilio V, Gourdine JL, Collier RJ (2012) Adaptation to hot climate and strategies to alleviate heat stress in livestock production animal 6:707-728. doi:10. 1017/S1751731111002448

Ripple WJ, Smith P, Haberl H, Montzka SA, McAlpine C, Boucher DH (2014) Ruminants, climate change and climate policy. Nat Clim Change 4:2-5. doi:10.1038/nclimate2081

Scandizzo PL (2011) Climate change adaptation and real option evaluation. A case study in Campeche, Mexico. Report to the World Bank

Schär C, Pier Luigi V, Luigi Pier, Lüthi D, Frei C, Häberli C, Liniger MA, Appenzeller C (2004) The role of increasing temperature variability in European summer heatwaves. Nature 427:332. doi: 10.1038 /nature 02300

Schmidt CW (2000) Lessons from the flood: will Floyd change livestock farming? Environ Health Perspect 108:A74-A77. doi: $10.2307 / 3454499$

Seo SN, Mendelsohn R (2008) Measuring impacts and adaptations to climate change: a structural Ricardian model of African livestock management. Agric Econ 38:151-165. http://www. blackwellpublishing.com/journal.asp?ref=0169-5150\&site $=1$

Settar P, Yalcin S, Turkmut L, Ozkan S, Cahanar A (1999) Season by genotype interaction related to broiler growth rate and heat tolerance. Poult Sci 78:1353-1358

St-Pierre NR, Cobanov B, Schnitkey G (2003) Economic losses from heat stress by US livestock industries1. J Dairy Sci 86(Suppl. 1). doi:10.3168/jds.S0022-0302(03)74040-5
Stott PA, Christidis N, Otto FEL, Sun Y, Vanderlinden JP, van Oldenborgh GJ, Vautard R, von Storch H, Walton P, Yiou P, Zwiers FW (2016) Attribution of extreme weather and climaterelated events. Wiley Interdiscip Rev Clim Change 7(1):23-41. doi: $10.1002 /$ wcc. 380

Taylor KE, Stouffer RJ, Meehl GA (2012) An overview of CMIP5 and the experiment design. Bull Am Meteorol Soc 93:464. doi:10.1175/BAMS-D-11-00094.1

Thornton PK (2010) Livestock production: recent trends, future prospects. Philos Trans R Soc Lond B Biol Sci 365:2853. doi:10. 1098/rstb.2010.0134

Triantaphyllou E (2000) Multi-criteria decision making methods: a comparative study. Kluwer Academic Publishers, Dordrecht

UNFCCC (2009) Potential costs and benefits of adaptation option: a review of existing literature. Technical paper

Van Dantzig D (1956) Economic decision problems for flood prevention. Econometrica 24:276-287. doi:10.2307/1911632

van Der Pol TD, van Ierland EC, Gabbert S, Weikard HP, Hendrix EMT (2015) Impacts of rainfall variability and expected rainfall changes on cost-effective adaptation of water systems to climate change. J Environ Manag 154:40-47. doi:10.1016/j.jenvman. 2015.02.016

Von Neumann J (1967) Theory of games and economic behavior. Wiley Science Edition edn. Wiley, New York

Watkiss P, Hunt A, Blyth W, Dyszynksi J (2014) The use of new economic decision support tools for adaptation assessment: a review of methods and applications, towards guidance on applicability. Climatic Change Special Issue on "Uncertainty and Climate Change Adaptation. doi:10.1007/s10584-014-12509

West JW, Mullinix BG, Bernard JK (2003) Effects of hot, humid weather on milk temperature, dry matter intake, and milk yield of lactating dairy cows. J Dairy Sci 86:232-242. doi:10.3168/jds. S0022-0302(03)73602-9

Wiersma F (1990) Temperature-humidity index table for dairy producer to estimate heat stress for dairy cows. Department of Agricultural Engineering, The University of Arizona, Tucson

Woodward M, Kapelan Z, Gouldby B (2014) Adaptive flood risk management under climate change uncertainty using real options and optimization. Risk Anal 34:75-92. doi:10.1111/risa.12088

Wreford A, Dittrich R (2015) Report on economic appraisal of adaptation options. Deliverable 11.3, Animal Change Project FP7-266018. Edinburgh 